\title{
THERAPEUTIC EFFECT OF NIGELLA SATIVA AND IVERMECTIN VERSUS ALBENDAZOLE ON EXPERIMENTAL TRICHINELLOSIS IN MICE
}

\author{
By \\ SOAD MAHDY NADA ${ }^{1}$, SAMIRA METWALLY MOHAMMAD ${ }^{1 *}$, HOWAYDA S. F. \\ MOAD $^{1}$, MAHMOUD A.EL-SHAFEY ${ }^{2}$, ASMAA M.FAROUK AL-GHANDOUR ${ }^{1}$ \\ AND NAGWA IBRAHIM ${ }^{1}$
}

Department of Medical Parasitology ${ }^{1}$, and Department of Clinical Pathology ${ }^{2}$, Faculty of Medicine, Zagazig University, Zagazig, Egypt

( ${ }^{*}$ Correspondence:samirametwally1971@gmail.com)

\begin{abstract}
Anthelminthics are used for trichinellosis elimination in intestine and encysted larvae in muscles. This study evaluated the effects of Nigella sativa, ivermectin versus albendazole on experimental trichinellosis. One hundred and twenty mice were orally infected with 200 larvae of T. spiralis/ mouse. Drugs were tested against mature worms in the small intestine at 7 days post infection (dpi) and encysted larvae at 35 dpi. Parasitological assessment by counting of adult worms and encysted larvae was done as well as histopathologically. Biochemical measuring of serum aspartate aminotransferase (AST), alanine aminotransferase (ALT), total protein, albumin, globulin, and urea, creatinine and creatinine phosphokinase (CPK) values was done. High significant reductions in mean adult count was detected in $N$. sativa prophylactic, ivermectin and albendazole treated mice with efficacies of $45.9 \%, 97.4 \%$ \& $83.6 \%$ respectively with mild significant reduction in N. sativa treated mice with percent reduction $26.5 \%$. At 35 dpi, there was high significant reduction in mean larval count as compared to the control infected mice with reduction of $43.7 \%, 65.3 \%, 99.4 \%$ \& $80 \%$ in $N$. sativa prophylactic, $N$. sativa treated, ivermectin and albendazole respectively. Reduction of AST, ALT, urea, creatinine and CPK levels but total proteins increased in all treated mice compared to corresponding infected non-treated ones. Ivermectin gave the best results and continued for treating T. spiralis.
\end{abstract}

Key words: Trichinellosis, Experimental mice, Treatment

\section{Introduction}

Trichinellosis is one of the wordwide zoonotic disease (Kaewpitoon et al, 2008). It is due to ingestion of the first-stage larvae of the nematode of the genus Trichinella in raw or undercooked meat of pigs and/or bear (CDC, 2015).

Trichinella spiralis is the first discovered species (pozio, 2007). It is the most virulent and pathogenic species in human. Although, 8 other species were reported all over the world in other mammals (Hosking et al, 1996), its higher pathogenicity compared with other species is due to large number of larvae produced by a gravid female (Pozio $e t$ $a l, 1992)$ and the intense immune reaction occurred in human relative to the other genotypes (Bruschi et al, 1999; Gomez Morales et al, 2002).

Trichinella infection in human host consists of two phases, an intestinal phase and a muscular phase. Following ingestion of in- fected under cooked meat, larvae are released upon gastric digestion in the new host, and the first-stage larval parasite reaches the intestine and develops into adult worm. After mating adult female sheds larvae that migrate to other organs through lymphovascular system. Developing larvae invade skeletal muscles forming nurse cell complex (Gottestein et al, 2009).

The pathology is characterized by inflammatory reaction in the tissues and other organs which manifested by high fever, diarrhea, myalgia, periorbital edema and serious complications as myocarditis. Death was due to inflammatory reaction in heart, lung and CNS (Capo and Despommier, 1996).

Albendazole and mebendazole are the main antihelminthic drugs used for treatment of trichinellosis (Gottstein et al, 2009). They inhibited the microtubule polymerization through selective binding to beta-tubulin monomer of the parasite, with little effect on 
binding of host tubulin (Aguayo-Ortiz et al, 2013). Albendazole has an advantage over the mebendazole as its recommended plasma levels are achieved in most patients so don't need monitoring, while that of mebendazole vary among patients, so need monitoring and dosing(Gottstein et al, 2009). They have limited bioavailability, a high degree of resistance and weak action against encysted larvae (Caner et al, 2008). An alternative effective and safe drugs was claimed (Yadav and Temjenmongla, 2012).

Ivermectin is the most essential anti helminthic drug available nowadays (McCavera et al, 2007). Ivermectin is a derivative that shows great potency and low toxicity (Fisher and Mrozik, 1992). The anti-Trichinella effects were by interfering with nervous system and muscle function, mainly by improving the inhibitory neurotransmission (Yates and Wolstenholme, 2004). Ivermectin in treatment of trichinellosis shows an effective action against the intestinal adult worms (De Muth, 2009), and larvicidal effect on migrating and muscular larvae (Arena et al, 1992).

Medicinal plant, Nigella sativa showed wide range of effects, as an anxiolytic, antiinflammatory, immunomodulatory, hypoglycemic, hypolipdemic, wound healing and diabetic embryopathy protective effects (Ahmed et al, 2017).

The present study assessed the effectiveness of Nigella sativa (black seeds), Ivermectin ${ }^{\circledR}$ and Albendazole ${ }^{\circledR}$ against different stages of Trichinella spiralis in mice.

\section{Materials and Methods}

Experimental study: One hundred and twenty eight Swiss albino mice (20-25gm) were obtained from Schistosomal Biological Unit, Theodor Bilharz Research Institute (TBRI). The mice were kept on a standard commercial pelleted diet with free accessible water all over the time of study. Trichinella spiralis (T. spiralis) was obtained from laboratory bred infected albino mice in Parasitology Department Faculty of Medicine, Tanta University.

Swiss Albino mice were divided into six groups. GA: 8 normal healthy non infected mice, GB: 24 infected controls, GC: 24 treated with $N$. sativa before infection (prophylactic), GD: 24 infected and treated with $N$. sativa, GE: 24 infected and treated with ivermectin and GF: 24 infected and treated with albendazole. Gs: B to F were subdivided into three equal subgroups: SGI were sacrificed on 7 dpi to see effects on intestinal phase, SGП were sacrificed on 35 dpi to detect effects on muscular phase, SGW were kept for 30 dpi blood samples to explore trichinosis effect and treatment on serum enzymatic activities.

Ethical aspects: Mice were maintained under convenient conditions following the recommendations of the National Institutes of Health Guidelines for Animal Experimentation. The study was approved by the ethical committee of Faculty of Medicine, Zagazig University.

Larval extraction and preparation of inoculums (Dunn and Wright, 1985): Digestion of muscles of infected mice (Five weeks post infection) by immersion in artificial gastric juice formed by adding $1 \%$ pepsin and $1 \%$ concentrated HCL in warm tap water. Incubation of the mixture at $37 \mathrm{C}^{\circ}$ for 2 hours during with continuous agitation by electric stirrer was done. The resulting filtrated fluid was by sieve $\left(50 \mathrm{mesh} / \mathrm{cm}^{2}\right)$, then by sieve $\left(200 \mathrm{mesh} / \mathrm{cm}^{2}\right)$. The collected larvae were washed two to three times with tap water and suspended in a conical flask for half an hour to help sedimentation. Supernatant fluid was discarded and sediment larvae were microscopically counted using hemocytometer. Concentration of counted larvae in fluid was adjusted to each $0.25 \mathrm{ml}$. containing 200 living larvae, the recommended dose for infection of every mouse. Before infection, mice were starved for 12 hours, then oral infected by $0.25 \mathrm{ml}$. $T$. spiralis larvae using a tuberculin syringe fitted with 18 gauge blunt needle to introduce infective larvae into mice stomach (Wassom et al, 1988).

Drugs: Nigella sativa extract was available as Baraka capsule (Pharco Co., Alex.) disso- 
lved in $250 \mathrm{ml}$ ethanol $3 \%$ to give $5 \mathrm{ml} / \mathrm{kg} /$ bodywt/day orally for 4 weeks before and post infection from $2^{\text {nd }}$ infection ( $\mathrm{Abu} \mathrm{El}$ Ezz, 2005).

Ivermectin as Ivomec 1\% injection (Dawaya, Egypt) given as a single subcutaneous dose $200 \mu \mathrm{g} / \mathrm{kg} / \mathrm{bodywt}$ at $1^{\text {st }}$ dpi.

Albendazole (Alzental) suspension (EIPICO) as $20 \mathrm{mg} / \mathrm{ml}$ was given in dose $50 \mathrm{mg} / \mathrm{kg}$ orally for 3 successive days starting from the $3^{\text {rd }}$ dpi (Attia et al, 2015).

Isolation and counting of adults in intestine of mice (Wakelin and Lioyed, 1976): In brief, intestine of mice in all subgroups I was opened longitudinally along its entire length and cut into two centimeters pieces and placed in normal saline at $37 \mathrm{C}^{\circ}$ for three to four hours. Intestine was shaken well in saline, rinsed in saline, removed and discarded. Adult sedimentation was done by standby the container for half an hour. Discard the supernatant fluid, adults in least amount of fluid was poured into a petri-dish and counted under a dissecting microscope.

Counting number of muscle larvae (Dunn and Wright, 1985): For all the subgroups $\Pi$, process was the same as that for preparing muscle larvae for infection, but here both dead larvae and living larvae were counted.

Histopathological examination (Drury and Wallington, 1980): One $\mathrm{cm}$ from mid intest- inal region was taken at $7 \mathrm{dpi}$ and a piece of diaphragm of infected mice was taken at 35 dpi, fixed in $10 \%$ formol-saline, dehydrated in ascending grades of ethanol, and cleared in xylol. Impregnation was done in pure soft paraffin for 2 hours at $55^{\circ} \mathrm{C}$ then hard paraffin sections of $5 \mu$ thickness were cut by microtome. Sections were stain in Hematoxylin and Eosin stain.

Biochemical assessment: Blood samples were withdrawn at $30 \mathrm{dpi}$ from retro-orbital vein using disposable capillary tube from mice in GA \& all subgroups Ш. Sera were separated and used to determine therapeutic effect of $N$. sativa, ivermectin and albendazole on serum biochemical parameters as renal parameters (urea, creatinine), liver parameters (total protein, albumin, globulin, AST \& ALT) and muscle enzyme (CPK).

Statistical analysis: Data were tabulated and analyzed using the SPSS program version 18.0. A probability of less than 0.05 was considered significant (Finney 1971).

\section{Results}

Adults count in small intestine at $7 \mathrm{dpi}$ in mice with treated different drugs showed highest percentage reduction in mean adult count with ivermectin $(97.4 \%)$ followed by albendazole $(83.6 \%)$, N. sativa prophylactic (45.9\%), and least with N. sativa $(26.5 \%)$

Table 1: Adult worm count (Mean \pm SD) in small intestine at $7 \mathrm{dpi}$.

\begin{tabular}{|l|l|l|l|l|}
\hline Group & Adult & R $\%$ & F. test & P. value \\
\hline GB $(n=8)$ & $38.63 \pm 4.69^{\mathrm{a}}$ & & & \\
\cline { 1 - 3 } GC $(\mathrm{n}=8)$ & $20.88 \pm 4.97^{\mathrm{b}}$ & $45.9 \%$ & \multirow{3}{*}{155.79} & \\
\cline { 1 - 3 } GD $(\mathrm{n}=8)$ & $28.38 \pm 3.25^{\mathrm{c}}$ & $26.5 \%$ & & $<0.001^{* *}$ \\
\hline GE $(\mathrm{n}=8)$ & $1.0 \pm 0.3^{\mathrm{d}}$ & $97.4 \%$ & & \\
\hline GF $(\mathrm{n}=8)$ & $6.3 \pm 2.1^{\mathrm{e}}$ & $83.6 \%$ & & \\
\hline
\end{tabular}

The larval count in skeletal muscle of all groups at 35 dpi: Treated mice showed high reduction in mean larval count of $T$. spiralis was with the ivermectin $(99.4 \%)$ followed by albendazole (80\%), N. sativa (65.3\%), and lastly $N$. sativa prophylactic $(43.7 \%)$.

Table 2: Mean larval count of T. spiralis in both control and treated groups at 35dpi.

\begin{tabular}{|c|c|c|c|c|}
\hline Group & larvae: Mean \pm SD & $\mathrm{R} \%$ & F. test & P. value \\
\hline $\mathrm{GB}(\mathrm{n}=8)$ & $205830 \pm 8999^{a}$ & & \multirow{5}{*}{185.69} & \multirow{5}{*}{$<0.001 * *$} \\
\hline $\mathrm{GC}(\mathrm{n}=8)$ & $115880 \pm 4433^{b}$ & $43.7 \%$ & & \\
\hline GD $(n=8)$ & $89795 \pm 6068^{c}$ & $65.3 \%$ & & \\
\hline $\mathrm{GE}(\mathrm{n}=8)$ & $1191.2 \pm 74.28^{\mathrm{d}}$ & $99.4 \%$ & & \\
\hline $\mathrm{GF}(\mathrm{n}=8)$ & $41166 \pm 2783^{\mathrm{e}}$ & $80 \%$ & & \\
\hline
\end{tabular}


Biochemical study at 30dpi (infected control) showed a significant increase in serum activates of AST, ALT, urea, creatinine, globulin \& CPK $(\mathrm{P}<0.001)$ as compared with healthy control. There was a significant decrease in serum levels of total protein and albumin $(\mathrm{P}<0.001)$ as compared with the healthy control. All treated groups showed significant decrease in serum activates of AST, ALT, urea, creatinine, globulin and CPK $(\mathrm{P}<0.001)$ when compared with their corresponding infected control group. A significant serum levels elevation of the total protein and albumin $(\mathrm{P}<0.001)$ was noticed in all treated groups as compared with corresponding infected control.

Table 3: Serum parameters (AST, ALT, globulin, total proteins, albumin, urea, creatinine and CPK in groups at 30 dpi:

\begin{tabular}{|c|c|c|c|c|c|c|c|c|}
\hline Group & GA $(n=8)$ & GB $(n=8)$ & $\mathrm{GC}(\mathrm{n}=8)$ & GD $(n=8)$ & $\mathrm{GE}(\mathrm{n}=8)$ & GF $(n=8)$ & F. test & P. value \\
\hline AST: (U/ML) & $123.2 \pm 4.2^{\mathrm{a}}$ & $178.2 \pm 4.3^{\mathrm{b}}$ & $158.2 \pm 4.3^{\mathrm{c}}$ & $161.2 \pm 4.2^{\mathrm{c}}$ & $130.2 \pm 3.4^{\mathrm{a}}$ & $130.3 \pm 3.5^{\mathrm{a}}$ & 242.6 & $<0.001 * *$ \\
\hline ALT: (U/ML) & $30.8 \pm 1^{\mathrm{a}}$ & $58.6 \pm 2.2^{b}$ & $49.0 \pm 2.2^{\mathrm{c}}$ & $42.0 \pm 2.2^{\mathrm{c}}$ & $38.0 \pm 4.1^{\mathrm{a}}$ & $40.0 \pm 4.2 \mathrm{a}$ & 88.98 & $<0.001$ ** \\
\hline Urea:(mg/dl) & $49.2 \pm 2.1^{\mathrm{a}}$ & $67.3 \pm 2.7^{b}$ & $57.2 \pm 2.7^{\mathrm{c}}$ & $58.2 \pm 2.7^{\mathrm{c}}$ & $51.4 \pm 2.3^{a}$ & $51.5 \pm 3.1^{\mathrm{a}}$ & 51.61 & $<0.001 * *$ \\
\hline Creat: $(\mathrm{mg} / \mathrm{dl})$ & $1.6 \pm 0.1^{\mathrm{a}}$ & $2.6 \pm 0.2^{b}$ & $2.2 \pm 0.1^{\mathrm{c}}$ & $2.3 \pm 0.1^{\mathrm{c}}$ & $2 \pm 0.1^{\mathrm{c}}$ & $2.1 \pm 0.1^{\mathrm{c}}$ & 59.02 & $<0.001 * *$ \\
\hline Protein: $(\mathrm{g} \%)$ & $5.0 \pm 0.1^{\mathrm{a}}$ & $3.3 \pm 0.3^{b}$ & $4.5 \pm 0.2^{c}$ & $4.3 \pm 0.2^{\mathrm{c}}$ & $4.9 \pm 0.2^{\mathrm{a}}$ & $4.8 \pm 0.2^{\mathrm{a}}$ & 119.5 & $<0.001 * *$ \\
\hline Albumin: (g\%) & $3.5 \pm 0.1^{\mathrm{a}}$ & $1.1 \pm 0.1^{\mathrm{b}}$ & $3.3 \pm 0.1^{\mathrm{a}}$ & $3.4 \pm 0.1^{\mathrm{a}}$ & $3.2 \pm 0.2^{\mathrm{a}}$ & $3.1 \pm 0.2^{a}$ & 33.67 & $<0.001 * *$ \\
\hline Globulin: (g\%) & $3.0 \pm 0.1^{\mathrm{a}}$ & $3.6 \pm 0.1^{b}$ & $3.2 \pm 0.1^{\mathrm{a}}$ & $3.15 \pm 0.1^{\mathrm{a}}$ & $3.04 \pm 0.1^{\mathrm{a}}$ & $3.09 \pm 0.1^{\mathrm{a}}$ & 36.14 & $<0.001 * *$ \\
\hline CPK: (IU/L) & $53 \pm 4.6^{\mathrm{a}}$ & $457 \pm 30.4^{b}$ & $252 \pm 23^{c}$ & $242 \pm 21^{c}$ & $120 \pm 13^{d}$ & $122 \pm 11^{\mathrm{d}}$ & 86.7 & $<0.001 * *$ \\
\hline
\end{tabular}

\section{Discussion}

Generally speaking, during the initial infection of $T$. spiralis, invasion of the intestines could result in diarrhea, abdominal pain, and vomiting (Gari-Toussaint et al, 2005). Migration of larvae to muscle, which occurred about a week after being infected, could cause swelling of the face, inflammation of the whites of the eyes, fever, muscle pains, and a rash. Minor infection might be without symptoms (Bein et al, 2012) The complications might include inflammation of heart muscle, central nervous system involvement, and inflammation of the lungs (Bruschi and Dupouy-Camet, 2014).

The present study showed that using $N$. sativa for 4 weeks as prophylactic resulted in significant reduction in the mean adult worm count $(45.9 \%)$ at 7 dpi., and significant reduction in mean larval count at $35 \mathrm{dpi}$ (43.7\%). Using $N$. sativa for 4 weeks post infection showed mild reduction in mean adult count of $T$. spiralis $(26.5 \%)$ at $7 \mathrm{dpi}$ with significant reduction in mean larval count $(65.3 \%)$ at 35 dpi. Thus, using N. sati$v a$ as prophylactic gave better results than as therapeutic in lowering the mean adult count, but as therapeutic gave better results in lowering the mean larval count than prophylactic. The anti-Trichinella effect of $N$. sativa when used for 4 weeks before infection caused significant reduction in mean adult and larval count by the stimulatory the immune system resulted in abortion of larval stages with stoppage of adult development. This result agreed with Mohamed et al. (2005) used $N$. sativa as treatment and found significant reduction in adult count $(30 \%)$, and reduction of larval count $(74.7 \%)$ when used $N$. sativa during intestinal phase but, mild reduction $(29.5 \%)$ during migratory phase. Abu El-Ezz (2005) found a significant reduction in adult $(45.3 \%)$ and larval count $(43.3 \%)$ as prophylactic more than treatment $40 \mathrm{dpi}$., and as treatment gave $(21.7 \%)$ reduction in adult and $(56.9 \%)$ in larval count. The mechanism was due to spasmolytic action through saponin-like effect that enhanced adult expulsion by intestinal movement (Boskabady et al, 2004). The immune mediated action involved hypersensitivity including secretion of IgE or protective IgA on intestinal mucosa surface (El Shazly et al, 2002). N. sativa stimulates immune cells and bone marrow by rising T4:T8 ratio and natural killer cells activity that led to increase in interferon production $\&$ antibodies producing $\mathrm{B}$ cells inducing humoral and cellular immune responses (AlGhamdi, 2001).

The present results showed that ivermectin in a single dose $200 \mathrm{ug} / \mathrm{kg}$ S.C. at $1^{\text {st }}$ day of infection gave significant reduction in mean adult $(97.4 \%)$ and larval (99.4\%). This 
agreed with El-Azzouni (1997) and Basyoni and El-Sabah (2013) they found reduction in adult count $(98.5 \%)$ and encysted larvae (76.5\%). But, Song-Mingxin et al. (2002) used ivermectin in dose $0.3 \mathrm{ml} / \mathrm{kg}$ found less effective on total adult count with reduction between $(47.5 \%$ \& $58.1 \%)$, and ivermectin more effective against encysted larvae (at 40dpi) with reduction in larval count ranging between $(72.0 \% \& 82.8 \%)$. Ivermectin interferred with nervous system and muscle function by improving inhibitory neurotransmission and binding to glutamate-gated chloride channels in membranes of nerves and muscle cells led to increase permeability to chloride ions causing cellular hyperpolarization, followed by paralysis and death (Yates and Wolstenholm, 2004). El-Azzouni (1997) found that ivermectin effected adults by topographic destruction and degeneration with subsequent reduction in larval count. In the present study, albendazole in dose $50 \mathrm{mg} / \mathrm{kg}$ for 3 successive days from the $3^{\text {rd }}$ day post infection caused significant reduction in mean adult $(83.6 \%)$ and larval count (80\%) compared to infected control. This agreed with Attia et al. (2015) who used albendazole in the same dose and found significant reduction in both adult $(94.2 \%)$ and larval (90.9\%). However, lower efficacies of albendazole against the encysted larval stages were reported (Shoheib et al, 2006; Shalaby et al, 2010). The differences in albendazole efficacies against both intestinal and muscular stages depend on dose, time, duration of treatment (Siriyasatien et al, 2003). Its mode of action is the inhibition of microtubule polymerization through selective binding to beta-tubulin monomer of the parasite, with little effect on binding of the host tubulin (Aguayo-Ortiz et al, 2013).

The present results showed significantly increased in levels of AST, ALT, urea, creatinine, CPK and globulin with significantly decrease in levels of total proteins and albumin in infected control group as compared with non-infected healthy mice. This change might be due to hepatic and renal damage caused by the migrating larvae (Gamble et $a l, 1997)$. This agreed with Mikhail (1979). While the decrease in total proteins, albumin levels may be due to damage of liver parenchyma by migrating larvae or hepatic affection by the parasite metabolic products (Mikhail et al, 1978). Globulin elevation may be due to the compensatory reaction to restore osmotic pressure in serum reduced due to low albumin level or to increased formation of antibodies against the parasite or its metabolic products (Reinhold, 1955). The results agreed with Soliman et al. (2011) and Basyoni and El-Sabah (2013).

In the present study, marked biochemical parameters improvement to normal values occurred in all mice treated with $N$. sativa, Ivemectin and Albendazole. This agreed with Soliman et al. (2011) they reported highly significant reduction in AST \& ALT, decrease in urea and creatinine levels and increase in total proteins and albumin after the early treatment with ivermectin as a single dose of $0.2 \mathrm{mg} / \mathrm{kg}$ S.C. injection at $4 \mathrm{dpi}$ which assessed the biochemical parameters at 30 dpi. They attributed this due to drugs larvicidal activity as animals were experimentally infected with $T$. spiralis and free from other parasites. The results also agreed with Basyoni and El-Sabah (2013).

In the present study, all treated mice showed mild increase in inflammatory cellular reaction in mid-intestinal region. Diaphragmatic muscle showed decrease in larval deposition with mild inflammatory reaction around. In infected control, there was necrosis and atrophy of intestinal villi with marked inflammatory reaction mainly eosinophils in lamina propria. The diaphragmatic muscle showed multiple larval deposition surrounded by marked inflammation. This agreed with Abu El Ezz (2005) and Soliman et al. (2011) they showed a high number of migrating larvae to diaphragm of untreated rats. Ivermectin as a single subcutaneous dose of $0.2 \mathrm{mg} / \mathrm{kg} /$ bodywt at $10^{\text {th }}$ day showed a reduction in number of larvae encysted in diaphragms of infected rats. Aver- 
mectin for field use gave significant larvicidal activity (Arena et al, 1992).

\section{Conclusion}

The outcome data showed that ivermectin gave the best results at dosage level and formulations. This recommended the effectiveness of $N$. sativa extract as trichinellosis effective treatment in experimental mice.

\section{References}

Abu El Ezz, NM, 2005: Effects of Nigella sati$v a$ and Allium cepa oils on Trichinella spiralis in experimentally infected rats. J. Egypt. Soc. Parasitol. 35, 2:511-23.

Ahmad, W, Zeenat, F, Ahmad, M, Ansari, N, 2017: Medicinal plants as potent diuretic: A review. Int. J. Adv. Pharm. Med. Bioallied. Sci. 122:1-8

Attia, RAH, Mahmoud, AE, Farrag, HM, Makboul, R, Mohamed, ME, et al, 2015: Effect of myrrh and thyme on Trichinella spiralis enteral and parenteral phases with inducible nitric oxide expression in mice. Mem. Inst. Oswaldo Cruz 110:1035-41.

Arena, JP, Liu, K, Paress, P, et al, 1992: Expression of a glutamate-activated chloride current in Xeopus oocyst injected with caenorhabditis elegans RNA: Evidence for modulation by Avermectin. Mol. Brain Res. 15:339-48.

Aguayo-Ortiz, R, Mendez-Lucio, O, MedinaFranco, JL, et al, 2013: Towards the identification of the binding site of benzimidazoles to I2tubulin of Trichinella spiralis: insights from computational and experimental data .J. Mol. Graph. Model 41:12-9.

Al-Ghamdi, MS, 2001: The anti-inflammatory, analgesic and antipyretic activity of Nigella sativa. J. Ethnopharmacol. 76:45-8.

Basyoni, MM, El-Sabah, AA, 2013: Therapeutic potential of myrrh and ivermectin against experimental Trichinella spiralis infection in mice. Korean J. Parasitol. 51, 3:297-304.

Bien, J, Näreaho, A, Varmanen, P, et al, 2012: Comparative analysis of excretory-secretory antigens of Trichinella spiralis and Trichinella britovi muscle larvae by two-dimensional difference gel electrophoresis and immunoblotting. Proteome Sci. 1010-9.

Boskabady, MH, Shirmohammadi, B, Jandaghi, P, et al, 2004: Possible mechanism(s) for the relaxant effect of aqueous and macerated from Nigella sativa on tracheal chains of guinea pig. BMC Pharmacol. 4:1-6.

Bruschi, F, Dupouy-Camet, J, 2014: Trichinellosis. In: Helminth Infections and Their Impact on Global Public Health. F. Bruschi (Ed.), Springer-Verlag Wien.

Bruschi, F, Pozio, E, Watanabe, N, et al, 1999: Anaphylactic response to parasite antigens: $\operatorname{IgE}$ and IgG1 independently induce death in Trichinella- infected mice. Int. Arch. Allergy Immunol. 119:291-6.

Caner, A, Doskaya, M, Degirmenci, A, et al, 2008: Comparison of the effects of Artemisia vulgaris and Artemisia absinthium growing in western Anatolia against trichinellosis (Trichinella spiralis) in rats. Exp. Parasitol. 119:173-9. Capo', V, Despommier, DD, 1996: Clinical aspects of infection with Trichinella spp. Clin. Microbiol. Rev. 9:47-54.

CDC, 2015: DPDx-Trichinellosis-index. www. cdc. gov. Archived from original on 2015-07-04. De Muth, JE, 2009: Overview of biostatistics used in clinical research. Amer. J. Hlth. Syst. Pharm. 66:70-81.

Drury, R, Wallington, E, 1980: Carlton's Histological Technique. $5^{\text {th }}$ edition. Oxford University Press. Oxford. New York.

Dunn, IJ, Wright, KA, 1985: Cell injury caused by Trichinella spiralis in the mucosal epithelium in mice. J. Parasitol. 71:757-66.

El-Azzouni, MZ, 1997: Effect of ivermectin onexperimental trichinosis. J. Egypt. Soc. Parasitol. 27, 2:331-40.

El-Shazly, AM, El-Shewey, K, El Hamshary, E, Habib, FSM, Morsy, TA, 2002: Mice immunization using crude Trichinella spiralis antigen. J. Egypt. Soc. Parasitol. 32, 2:391-403.

Finney, DJ, 1971: Probity Analysis. Third edition. Cambridge University Press.

Fisher, MH, Mrozik, H, 1992: The chemistry and pharmacology of avermectins. Ann. Rev. Pharmacol. Toxicol. 32:537-53.

Gamble, H, Wisnewski, N, Wasson, L, 1997: Diagnosis of trichinellosis in swine by enzyme immunoassay using a synthetic glycan antigen. Am. J. Vet. Res. 58:1417-21.

Gomez Morales, MA, Mele, R, Sanchez, M, et al, 2002: Increased CD8+ -T cell expression and type 2 cytokine pattern during the muscular phase of Trichinella infection in humans. Infect. Immunol. $170: 233-9$. 
Gari-Toussaint, M, Tieulié, N, Baldin, JL, et al, 2005: Human trichinellosis due to T. britovi in southern France after consumption of frozen wild boar meat. Eurosurveillance. 10:550-60.

Gottestein, B, Pozio, E, Nockler, K, 2009: Epiolemiology, diagnosis, treatment and control of tri-chinellosis. Clin. Microbiol. Rev. 22:127-45.

Hosking, BC, Watson, TG, Leathwick, DM, 1996: Multigeneric resistance to oxfendazole by nematodes in cattle. Vet. Rev. 138:67-8.

Kaewpitoon, N, Kaewpitoon, SJ, Pengsaa, P, 2008: Food-borne: Parasitic zoonosis: distribution of trichinellosis in Thailand. Wld. J. Gastroenterol. 3:471-5.

McCavera, S, Walsh, TK, Wolstenholme, AJ, 2007: Nematode ligand-gated channels: an appraisal of their involvement in macrocyclic lactone resistance and prospects for developing molecular markers. Parasitol. 134:1111-21.

Mikhail, E, 1979: The occurrence of $T$. spiralis larvae in tissues other than skeletal muscles. J. Egypt. Soc. Parasitol. 9, 1:269-72.

Mikhail, E, Milad, M, Sabet, S, 1978: Experimental trichinosis: A pathological study of hepatic, renal and gonadal involvement .J. Egypt. Publ. Hlth. Assoc. 53:327-31.

Mohamed, AM, Metwally, NM, Mahmoud, S, 2005: Sativa seeds against $S$. mansoni different stages. Mem. Inst. Oswaldo Cruz. 100, 2:205-11. Pozio, E, 2007: Taxonomy, Biology and Epidemiology of Trichinella parasites. In: DupouyCamet, J, Murrell, KD (eds.) FAO/WHO/OIE Guidelines for the Surveillance, Management, Prevention and Control of Trichinellosis: World Organization for Animal Health Press, France.

Pozio, E, La Rosa, G, Murrell, KD, et al, 1992: Taxonomic revision of the genus Trichinella. J. Parasitol. 78:654-9.

Reinhold, JG, 1955: Chemical evaluation of the function of the liver. J. Clin. Chem. 1:351-421.

Shalaby, MA, Moghzy, FM, et al, 2010: Effect of methanolic extract of Balanites aegyptiacae fruits on enteral and parenteral stages of $T$. spiralis in rats. Parasitol. Res. 107:17-25.

Shoheib, ZS, Shamloula, MM, Abdin, AA, et al, 2006: Role of $\alpha$-chemotrypsin and colchicine as adjuvant therapy in experimental muscular trichinellosis: Parasitological, biochemical and immunohistochemical study. EJMM. 15:773-7

Siriyasatien, P, Yingyourd, P, Nuchprayoon, S, 2003: Efficacy of albendazole against early and late stage of Trichinella spiralis infection in mice. J. Med. Assoc. Thailand 86:S257-62.

Soliman, GA, Taher, ES, Mahmoud, MA, 2011: Therapeutic effects of Dormectin, ivermectin and levamisole against different stages of Trichinella spiralis in rats. Turk. Parasitol. Deg. 35:86-91.

Song-Mingxin, L, Yixin Zhang, X, Hui, H, et $a l$, 2002: Efficacy of ivermectin and albendazole against the various phases of 4 Trichinella isolates in treating mice. Chin. J. Zoon. 18:89-91.

Wakelin, D, Lioyd, M, 1976: Immunity to primary and challenge infection of Trichinella spiralis in mice a re-examination of conventional parameters. Parasitol. 71:173-82.

Wassom, DL，Dougherky，DA，Dick，KA, 1988: $T$. spiralis infections of inbred mice: Immunological specific responses induced by different Trichinella isolates. J. Parasitol. 2: 283-7. Yadav, AK, Temjenmongla, A, 2012: Efficacy of Lasia spinosa leaf extract in treating mice infected with T. spiralis. Parasitol. Res. 110, 1:493. Yates, DM, Wolstenholm, AJ, 2004: An ivermectin-sensitive glutamate gated chloride channel subunit from Dirofilaria immitis. Int. J. Parasitol. 34, 9:1075-81.

\section{Explanation of Figures}

Fig. 1: Section in small intestine of infected control showed epithelial hyperplesia (yellow arrow), inflammatory reaction in lamina propria (green arrow) and edema (red arrow) (X100, H\&E)

Fig. 2: Section in small intestine of infected control showed necrosis and atrophy of villi (green arrow) (X100,H\&E)

Fig. 3: Section in small intestine (lamina propria) of Ni.sativa prophylactic showed mild increase in inflammatory cellular reaction (red arrow) (X100, H\&E).

Fig. 4: Section in small intestine of Ivermectin treated showed mild inflammation with eosinophils infiltrate (red arrow) (X100, H\&E).

Fig. 5: Section in small intestine of Albenazole treated showed mild inflammation with eosinophils infiltrate (red arrow) (X100, H\&E).

Fig. 6: Section in muscle of diaphragm of infected control showed multiple larval deposition (red arrow) (X100, H\&E)

Fig. 7: Section in muscle of diaphragm of infected control showed multiple larval deposition (red arrow) and marked muscle inflammation (black arrow). (X100, H\&E).

Fig. 8: Section in muscle of diaphragm of $N$. sativa treated showed single larval deposition (black arrow) surrounded by mild muscle inflammation (green arrow), (X400, H\&E).

Fig. 9: Section in muscle of diaphragm of Ivermectin treated showed single larval deposition (red arrow) surrounded by mild muscle inflammation (black arrow), (X400, H\&E).

Fig. 10: Section in muscle of diaphragm of Albenazole treated showed single larval deposition (red arrow) surrounded by muscle inflammation (black arrow), (X400, H\&E). 

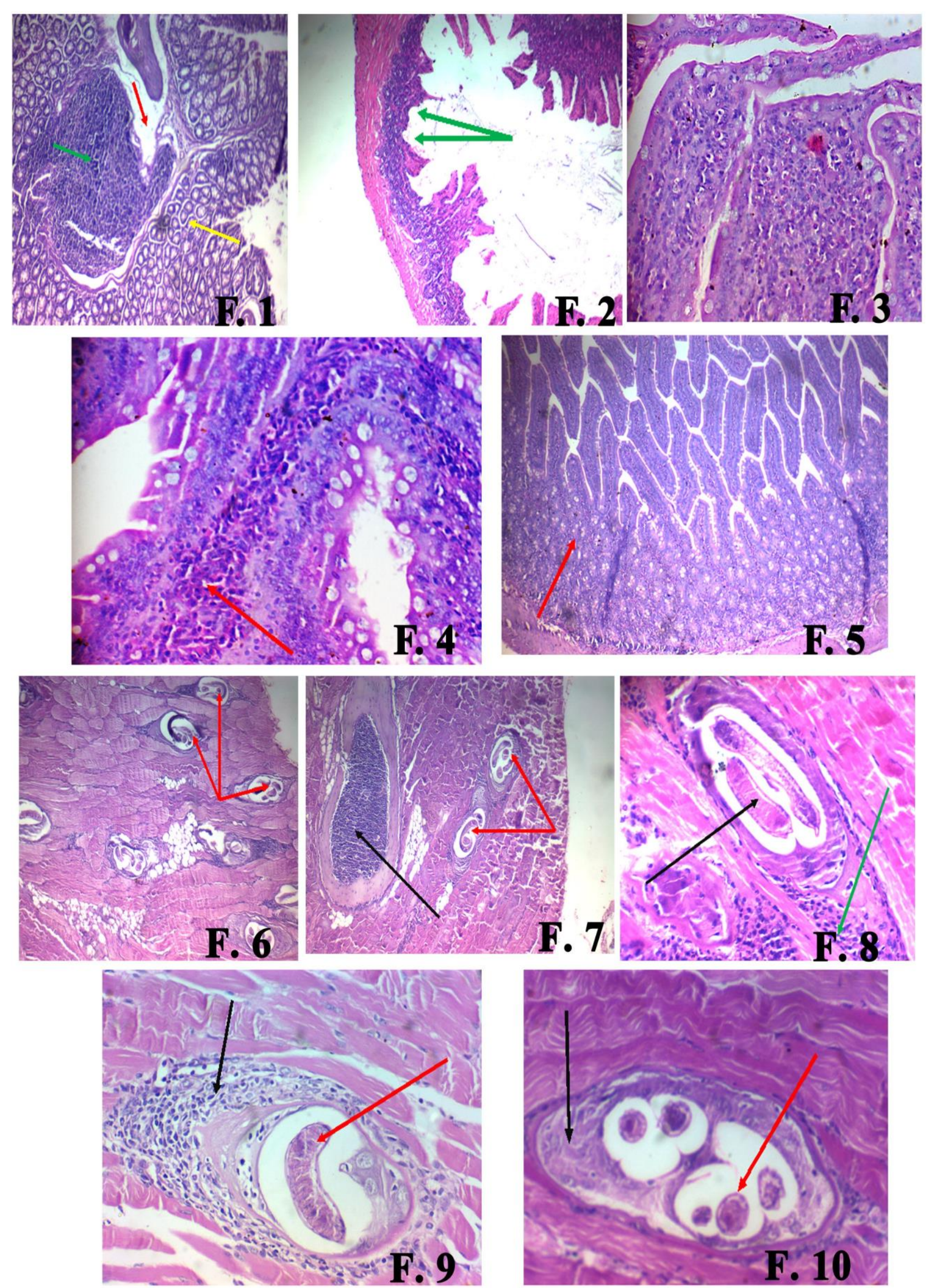